\title{
Black Silicon With Ultra-Low Surface Recombination Velocity Fabricated by Inductively Coupled Power Plasma
}

\author{
landolo, Beniamino; Sánchez Nery, Adriana P.; Davidsen, Rasmus S.; Hansen, Ole
}

Published in:

Physica Status Solidi - Rapid Research Letters

Link to article, DOI:

10.1002/pssr.201800477

Publication date:

2019

Document Version

Peer reviewed version

Link back to DTU Orbit

Citation (APA):

landolo, B., Sánchez Nery, A. P., Davidsen, R. S., \& Hansen, O. (2019). Black Silicon With Ultra-Low Surface Recombination Velocity Fabricated by Inductively Coupled Power Plasma. Physica Status Solidi - Rapid Research Letters, 13(2), [1800477]. https://doi.org/10.1002/pssr.201800477

\section{General rights}

Copyright and moral rights for the publications made accessible in the public portal are retained by the authors and/or other copyright owners and it is a condition of accessing publications that users recognise and abide by the legal requirements associated with these rights.

- Users may download and print one copy of any publication from the public portal for the purpose of private study or research.

- You may not further distribute the material or use it for any profit-making activity or commercial gain

- You may freely distribute the URL identifying the publication in the public portal 


\title{
Black silicon with ultra-low surface recombination velocity fabricated by inductively coupled power plasma
}

\author{
Beniamino Iandolo*, Adriana P. Sánchez Nery, Rasmus S. Davidsen, Ole Hansen \\ Department of Micro- and Nanotechnology, Technical University of Denmark, building \\ 345C, DK-2800 Kgs. Lyngby, Denmark \\ *Corresponding author: benian@nanotech.dtu.dk
}

\begin{abstract}
Black silicon is a naturally antireflective Si surface with great potential for high-efficiency solar cells. In particular, black silicon surfaces can be obtained using reactive ion etch in a maskless, single-step process regardless of crystallinity and with minimal material loss. Surface damage from the etching process, however, result in surfaces with high recombination velocity, thus limiting solar cell efficiency. We have developed a method to texture Si surfaces using noncryogenic reactive ion etch with a plasma sustained exclusively by inductively coupled power, thereby minimizing surface damage. We achieved a target reflectance of $3 \%$ or lower in the wavelength range 300-1000 $\mathrm{nm}$ after an etch time of $2 \mathrm{~min}$. Surfaces coated with $\mathrm{Al}_{2} \mathrm{O}_{3}$ deposited by atomic layer deposition showed recombination velocity as low as $6.9 \mathrm{~cm} \mathrm{~s}^{-1}$ on $\mathrm{p}$ type Czochralski wafers, almost the same values as measured on planar reference surfaces (6.8 $\mathrm{cm} \mathrm{s}^{-1}$ ). This corresponds to an implied open circuit voltage as high as $757 \mathrm{mV}$ for a cell with thickness of $180 \mu \mathrm{m}$ and base resistivity of $4 \Omega \mathrm{cm}$. These results indicate that our method for texturing of Si surfaces is suitable for fabrication of high-efficiency single junction Si solar cells.
\end{abstract}

Key Words: black silicon, reactive ion etch, surface damage, surface passivation 


\section{Introduction}

Black silicon (b-Si) ${ }^{[1-3]}$ has shown great potential as surface texturing for silicon photovoltaics thanks to its ultra-low reflectance for mono- and multi-crystalline $\mathrm{Si}$ at normal and varying incident angle ${ }^{[4,5,14,15,6-13]}$. This relaxes requirements on antireflective properties of front surface passivation coatings ${ }^{[16-18]}$. B-Si can be obtained using a variety of dry etch methods, among which atmospheric pressure dry etch (ADE) and plasma-based reactive ion etch (RIE) are very promising. ADE is a relatively fast, mask-less and plasma-free etching technique able to decrease reflectance of silicon down to around $10 \%$ in 1 minute of etching time ${ }^{[19,20]}$, and has been used to fabricate PERC solar cells on multicrystalline Si with efficiency reaching $20 \%{ }^{[21]}$. Similar to ADE, RIE texturing is also of commercial interest because: (i) it is a mask-less, single-step process, and therefore potentially scalable; (ii) it can be used to texture diamondwire cut multi-crystalline Si wafers and very thin Si wafers with minimal material loss, both of which will likely play a significant role in the future solar cell market ${ }^{[22]}$. b-Si surfaces obtained by RIE consist typically of nanostructures of various shapes with characteristic dimensions between a few hundred $\mathrm{nm}$ and a few $\mu \mathrm{m}$ with no long-range spatial ordering, generated by a delicate balance between isotropic chemical etch and anisotropic physical etch of the $\mathrm{Si}$ surface ${ }^{[23,24]}$, and the resulting averaged reflectance is often lower than $1 \%{ }^{[2]}$, i.e. a significant improvement over ADE. The power conversion efficiency of solar cells with RIE texturing has surpassed $22 \%$ and $20 \%$ for mono- and multicrystalline Si substrates, respectively ${ }^{[25-28]}$. The current show-stopper for solar cells with b-Si texturing is the increased surface recombination resulting in lower open circuit voltage $\left(V_{\mathrm{oc}}\right)$ compared to the best conventionally-textured $\mathrm{Si}$ solar cells. The increased surface recombination arises mainly from the etch damage induced during RIE. In order to capitalize on the superior optical properties of b-Si, surface recombination must therefore be reduced to levels similar to those measured on competing texturing technologies. Recently, b-Si surfaces characterized by lower recombination rates have been fabricated by decreasing the capacitively coupled power (CCP) during plasma processing ${ }^{[7,29,30]}$, leading to a lower kinetic energy of ions and thus reduced surface damage, as confirmed by high-resolution transmission electron microscopy characterization of individual nanostructures ${ }^{[7]}$. However, that process still required a certain amount of CCP and etching time $\geq 10 \mathrm{~min}$ to reach the desired antireflective properties, which is not convenient in view of process scalability. We have successfully addressed these issues and we present in this work a superior method for fabrication of b-Si by RIE. In particular: (i) we fabricated the b-Si surface without the use of CCP, and relied exclusively on the inductively coupled power (ICP) 
in our RIE equipment; (ii) we achieved excellent antireflective properties (total reflectance lower than 3\% in the wavelength range 300-1000 nm) after 2 min of etching; and (iii) we achieved state-of-the-art effective minority carrier lifetime values in excess of $3 \mathrm{~ms}$ on $p$-type Czochralski (CZ) Si, corresponding to surface recombination velocity values of $6.9 \mathrm{~cm} \mathrm{~s}^{-1}$ for textured surfaces, after passivation with $\mathrm{Al}_{2} \mathrm{O}_{3}$.

\section{Results and Discussion}
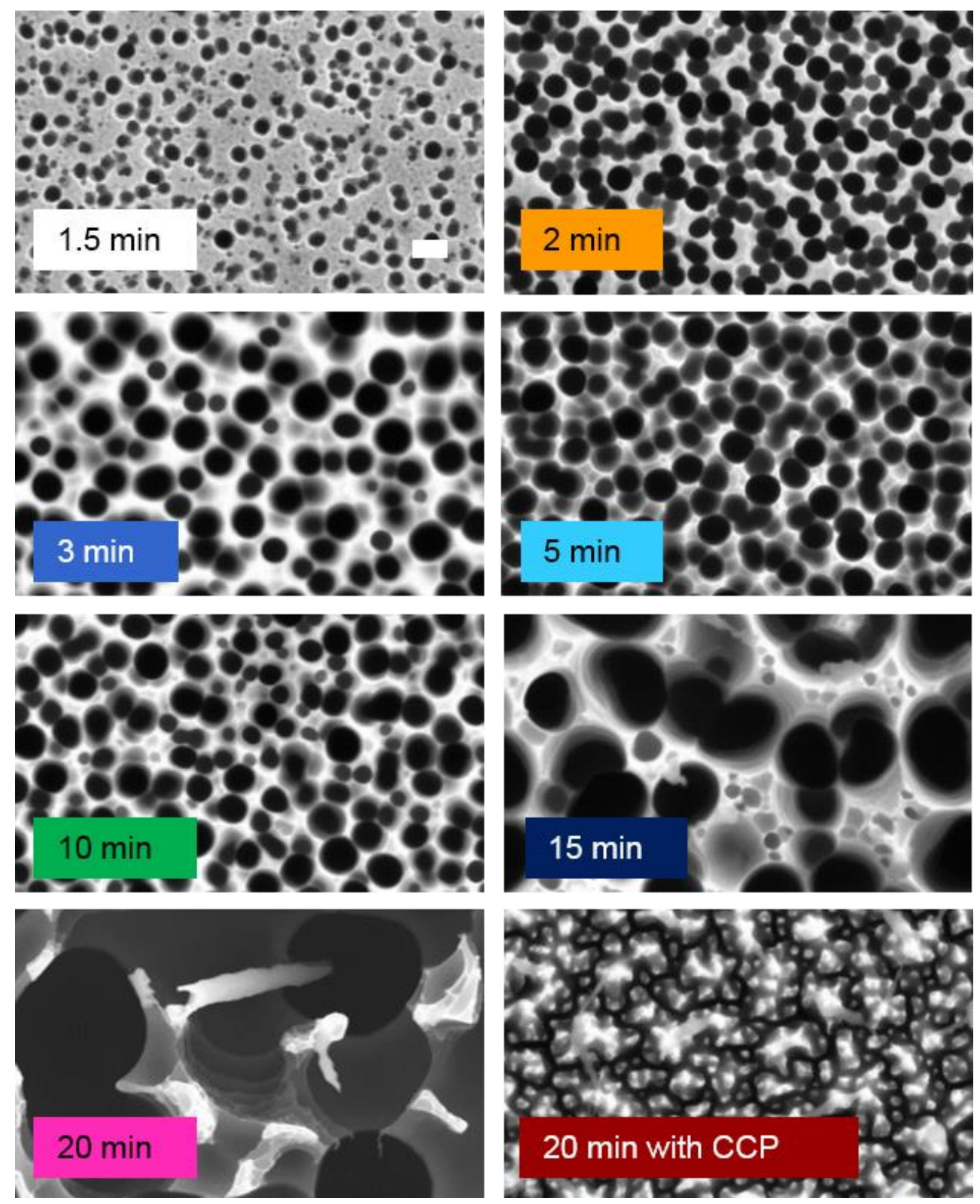

Figure 1. Top-view SEM images of surfaces after RIE texturing, before coating with $\mathrm{Al}_{2} \mathrm{O}_{3}$ and annealing. The texturing time $t_{\mathrm{RIE}}$ is indicated in the bottom left corner of each image. The scale bar represents $200 \mathrm{~nm}$ for all images. 
When fabricating b-Si by RIE, both CCP and ICP are usually employed. It is usually assumed that the ICP regulates the density of the plasma, while the CCP independently determines the substrates bias voltage, and thus the kinetic energy of the ions. A comparatively low substrate bias voltage is however still present even when CCP is not used due to the large difference in mobility between electrons and ions. Thus, even without CCP, an electrical potential difference is still present between the positively charged ions in the plasma and the substrate. This selfbias effect is responsible for the slight anisotropy of the etching process, which enables the formation of $b-S i$ nanostructures even relying only on ICP to start the plasma.

Here, we fabricated $b$-Si by RIE using either ICP or CCP, keeping the ratio between $\mathrm{SF}_{6}$ and $\mathrm{O}_{2}$ flows in the plasma as well as total pressure and process temperature $\left(0{ }^{\circ} \mathrm{C}\right)$ constant, and varying the etching time $t_{\text {RIE. }}$. Figure 1 shows top-view scanning electron microscopy (SEM)

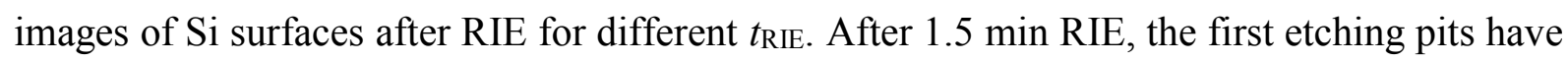
formed with roughly circular cross-section and various diameters. This is in agreement with the current understanding of formation of $\mathrm{b}-\mathrm{Si}$, which starts from etching of the native silicon oxide at a faster rate at random spots on the surface due to variations in thickness and/or density ${ }^{[1]}$. For $t_{\mathrm{RIE}}=2 \mathrm{~min}$, the pits start overlapping. The average diameter of etching pits remains rather similar (between 100 and $250 \mathrm{~nm}$ ) for $t_{\mathrm{RIE}}$ up to $10 \mathrm{~min}$, while it becomes considerably larger $\left(\geq 400 \mathrm{~nm}\right.$ ) for $t_{\mathrm{RIE}}$ of 15 and $20 \mathrm{~min}$, with some scallops visible on the sides of the etching pits. When ICP is replaced by CCP a completely different geometry of the nanostructures results after etching for $20 \mathrm{~min}$, characterized by hillocks with various shapes, some of which are connected by Si protrusions.

Cross-section SEM characterization of the surfaces after coating with $\mathrm{Al}_{2} \mathrm{O}_{3}$ deposited by atomic layer deposition (ALD) for passivation purposes is summarized in Fig. 2. It is clear that the height of the nanostructures increases with $t_{\mathrm{RIE}}$, and that the $\mathrm{Al}_{2} \mathrm{O}_{3}$ coating is conformal as expected by an ALD process. In addition, for $t_{\mathrm{RIE}} \geq 10 \mathrm{~min}$ the etching pits have a paraboloidlike shape. Interestingly, the height of the nanostructures for the surface etched with CCP is approximately one third of that of the nanostructures resulting from employing ICP for the same $t_{\mathrm{RIE}}$ (around $500 \mathrm{~nm}$ and $1.5 \mu \mathrm{m}$, respectively). 

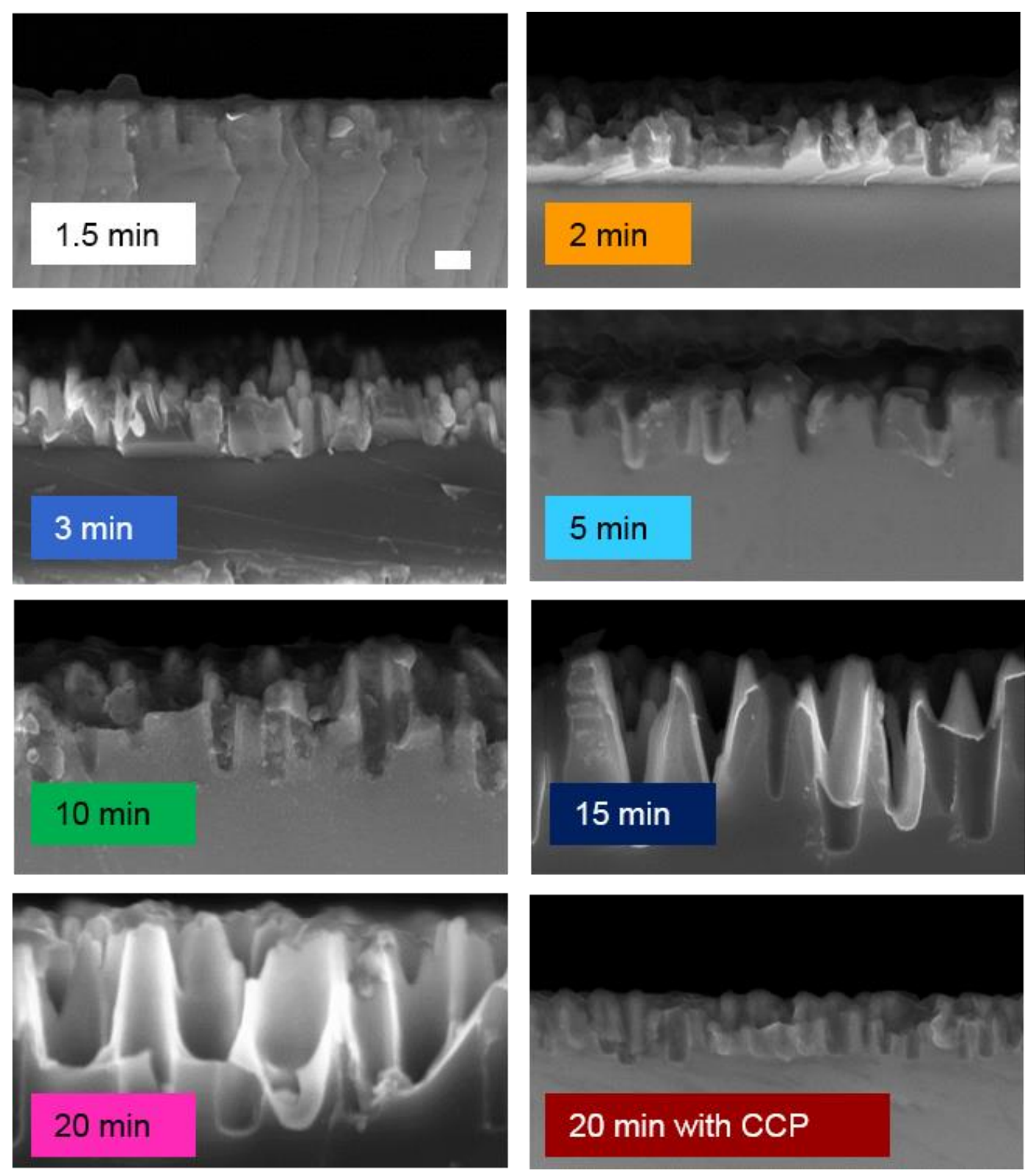

Figure 2. Cross-section SEM images of surfaces after RIE texturing, coating with $\mathrm{Al}_{2} \mathrm{O}_{3}$ and annealing. The texturing time $t_{\mathrm{RIE}}$ is indicated in the bottom left corner of each image. The scale bar represents 200 $\mathrm{nm}$ for all images.

Figure 3(a) shows the total (sum of diffuse and specular) optical reflectance $R$ as function of photon wavelength $\lambda$ in the range 300-1100 nm measured using an integrating sphere. For $t_{\mathrm{RIE}}$ $=1.5 \mathrm{~min}, R$ is above $2 \%$ for $300 \mathrm{~nm} \leq \lambda<700 \mathrm{~nm}$ and above $5 \%$ for $700 \mathrm{~nm} \leq \lambda<1100 \mathrm{~nm}$, whereas $t_{\mathrm{RIE}}=2$ min already results in $R$ values lower than $3 \%$ for $300 \mathrm{~nm} \leq \lambda<1000 \mathrm{~nm}$. For $t_{\mathrm{RIE}}=3 \mathrm{~min}, R$ is reduced to below $2 \%$ for $300 \mathrm{~nm} \leq \lambda<800 \mathrm{~nm}$. 

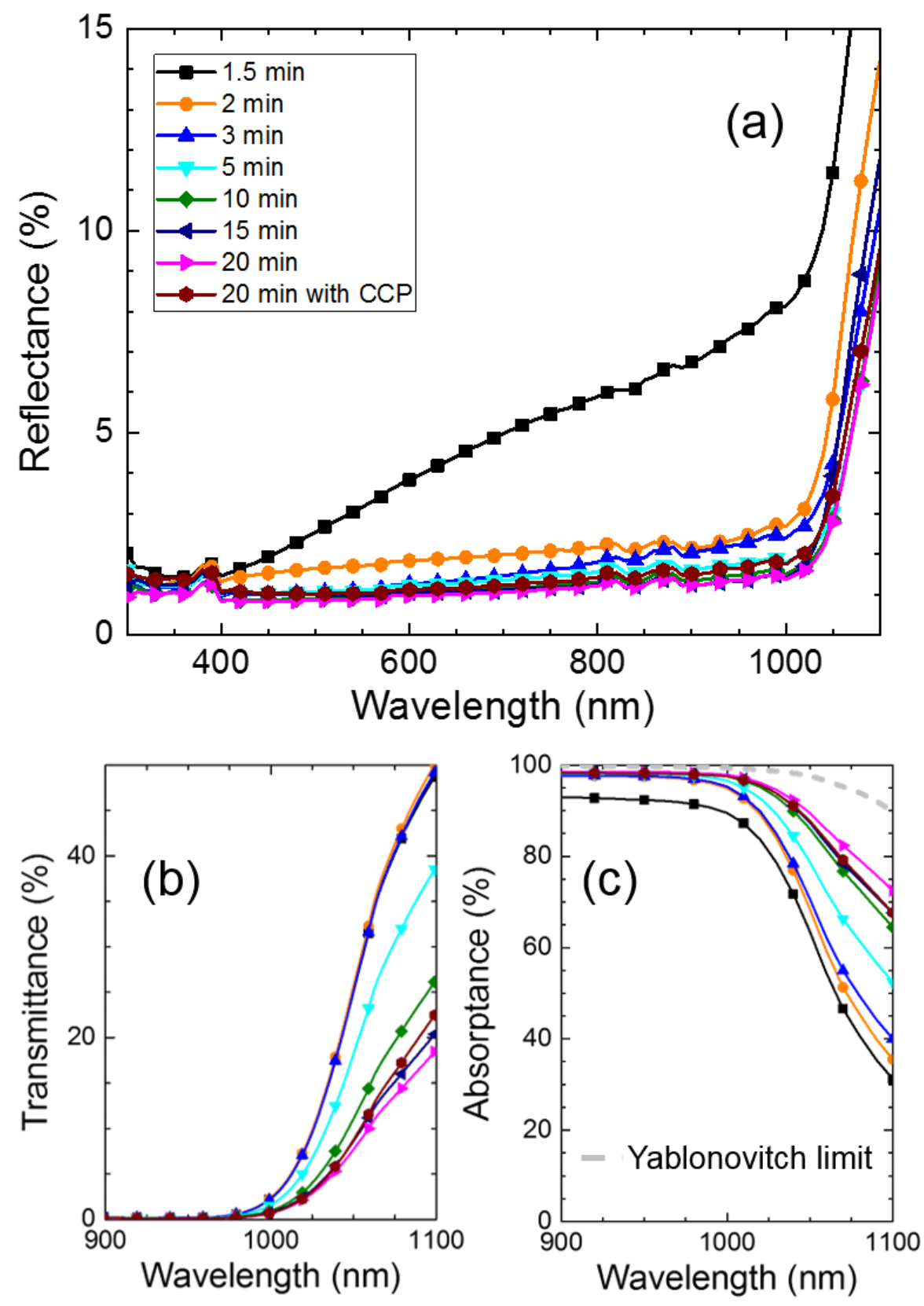

Figure 3. Optical properties of wafers with one surface textured by RIE, before ALD coating and annealing. (a) Reflectance of the front surface. (b) Transmittance through the wafer. (c) Absorptance. The legend is the same for all plots. The grey dashed line in panel (c) shows the absorption in the ideal Yablonovitch limit.

For $t_{\mathrm{RIE}} \geq 5 \mathrm{~min}, R$ is very similar and lower than $2 \%$ in the full measurement range. The measured reflectance is slightly higher than what has been obtained previously using RIE texturing, where values down to less than $1 \%$ at normal incidence ${ }^{[3,25,27]}$ were obtained. We notice that the wafers used for this study are double-side mirror-polished, which have an initial 
higher $R$ than saw-damaged removed, solar-grade wafers. In addition, we expect that the $R$ will further decrease upon coating the textured surface with passivation/antireflection stacks (typically $\mathrm{SiN}_{\mathrm{x}}: \mathrm{H}, \mathrm{Al}_{2} \mathrm{O}_{3}$ or a combination of the two), thus eliminating front reflection losses as efficiency bottleneck. Furthermore, we note that the values of $R$ obtained here with $t_{\mathrm{RIE}}=5$ min are roughly half of those measured by Hirsch et al. using a similar ICP process with same $t_{\mathrm{RIE}}{ }^{[31]}$. The optical transmittance $T$ through the wafers is also affected by the front texturing size, as shown in Figure 3(b). In particular, $T$ is practically the same for $t_{\mathrm{RIE}}$ between 1.5 and 3 min, rising steeply from around 0 at $1000 \mathrm{~nm}$ to $50 \%$ at $1100 \mathrm{~nm}$. Increasing $t_{\mathrm{RIE}}$ to 5 or $10 \mathrm{~min}$ results in $T$ below $40 \%$ and $25 \%$ at $1000 \mathrm{~nm}$, respectively. Finally, $T$ is similar and at maximum around $20 \%$ for $t_{\mathrm{RIE}} \geq 15 \mathrm{~min}$ (including the wafer textured using CCP). It follows from these measurements that $t_{\mathrm{RIE}}$ of at least $10 \mathrm{~min}$ is required to obtain respectable light-trapping properties. Figure 3(c) shows the optical absorption $A$ calculated by subtracting the measured $R$ and $T$ from $100 \%$. The variation in $T$ is larger than that in $R$ and this determines the trend for $A$. For comparison, the absorptance in the theoretical Yablonovitch limit $A$ Yabl is also plotted according to the formula ${ }^{[32]}$ :

$$
A_{\text {Yabl }}=1-\frac{1}{1+4 n_{\mathrm{Si}}^{2} \alpha_{\mathrm{Si}} W},
$$

where $n_{\mathrm{Si}}$ and $\alpha_{\mathrm{Si}}$ are the refractive index and the absorption coefficient of $\mathrm{Si}$, respectively. We note that the Yablonovitch limit is found for isotropic illumination and zero front surface reflection. A Lambertian limit for absorptance that takes into account reflection at the front surface is described in the Supplementary Information (Section S1).

Figure 4 shows effective minority carrier lifetime $\tau_{\text {eff }}$ as function of $t_{\mathrm{RIE}}$, averaged over an area with diameter of $100 \mathrm{~mm}$ for each wafer. Measurements were carried out within $1 \mathrm{~h}$ after postALD annealing, and then repeated several times over a period of around $300 \mathrm{~h}$, in order to evaluate possible degradation effects of the $\mathrm{Al}_{2} \mathrm{O}_{3}$ passivation. $\tau_{\text {eff }}$ degraded with time and stabilized within $200 \mathrm{~h}$; the initial value could be recovered after hotplate annealing for $10 \mathrm{~min}$ at temperature as low as $150{ }^{\circ} \mathrm{C}$, as shown in Fig. S1 (Supplementary information). This behavior suggests intercalation of water during storage of the wafers as a likely reason for the decrease of $\tau_{\text {eff. Degradation of } \mathrm{Al}_{2} \mathrm{O}_{3} \text { passivation has been observed in previous studies }}{ }^{[33-35]}$ and can be prevented by using for instance a $\mathrm{SiN}_{\mathrm{x}}$ :H capping layer, as shown in Fig. S2 for nontextured surfaces. Immediately after post-ALD annealing, we measured average $\tau_{\text {eff }}$ longer than $3 \mathrm{~ms}$ for $t_{\mathrm{RIE}}$ between 1.5 and $2 \mathrm{~min}$ and between 2.5 and $3 \mathrm{~ms}$ for $t_{\mathrm{RIE}} \geq 3 \mathrm{~min}$. The average $\tau_{\mathrm{eff}}$ 
of the non-textured wafer reference sample is $3.7 \mathrm{~ms}$. We note that the average $\tau_{\mathrm{eff}}$ for $t_{\mathrm{RIE}} \leq 3$ min is within one standard deviation of the average for the $\tau_{\text {eff }}$ non-textured wafer. Texturing the Si using CCP instead of ICP results in a much lower average $\tau_{\text {eff }}$ of $0.89 \mathrm{~ms}$. $\tau_{\text {eff }}$ stabilized to values higher than $1.5 \mathrm{~ms}$ for $t_{\mathrm{RIE}} \leq 3 \mathrm{~min}$ and lower than $1 \mathrm{~ms}$ for longer $t_{\mathrm{RIE}}$. These results illustrate the effect of platen power on the resulting minority carrier lifetime of RIE-textured samples. Based on the combination of

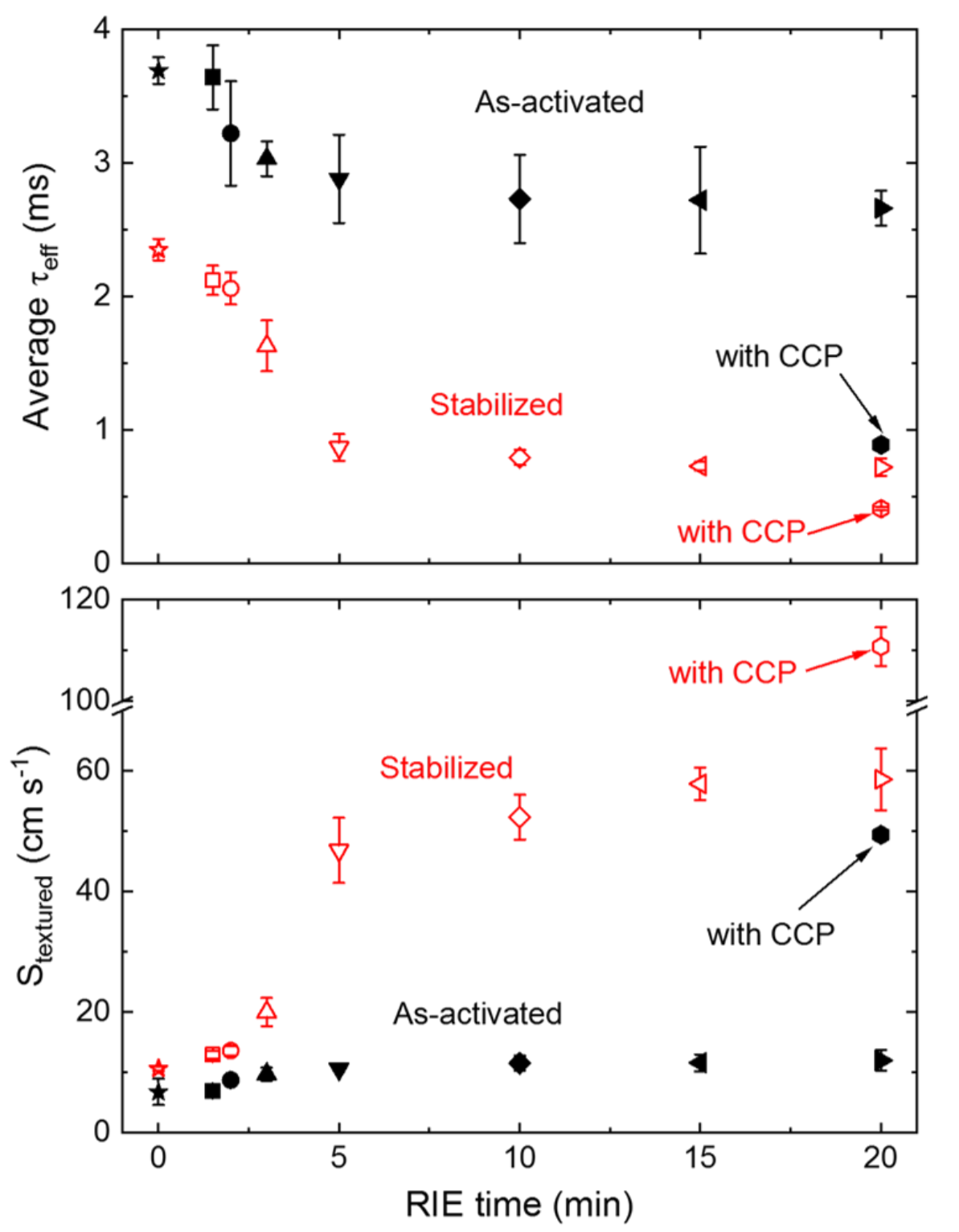

Figure 4. Top: average values of minority carriers effective lifetime $\tau_{\mathrm{eff}}$ as function of etching time $t_{\mathrm{RIE}}$ mapped over $100 \mathrm{~mm}$ diameter surfaces, including a wafer textured using CCP. Error bars indicate one standard deviation from the average. Bottom: average effective surface recombination velocity of textured surfaces $S_{\text {textured. }}$ Error bars indicate one standard deviation from the average. Open symbols indicate values measured within $1 \mathrm{~h}$ of $\mathrm{Al}_{2} \mathrm{O}_{3}$ activation by post-ALD annealing. Closed symbol indicate values measures after stabilization of surface passivation. 
optical and lifetime measurements, it appears that RIE texturing for 2 or 3 min provides the best compromise between optical reflectance and surface damage, even though longer $t_{\mathrm{RIE}}$ is needed to achieve the best light trapping properties. The effective lifetime can be decomposed into contributions from the bulk and from the surfaces according to the following equation:

$$
\frac{1}{\tau_{\text {eff }}}=\frac{1}{\tau_{\text {bulk }}}+\frac{S_{\text {front }}+S_{\text {back }}}{W}
$$

Where $\tau_{\text {bulk }}$ is the bulk lifetime and $S_{\text {front }}$ and $S_{\text {back }}$ are the surface recombination velocity at the front and back surfaces, respectively. Assuming $\tau_{\text {eff }}<<\tau_{\text {bulk, }}$, for a non-textured wafer $S_{\text {front }}=$ $S_{\text {back }}=S_{\text {planar }}$ and one can write $1 / \tau_{\text {eff }}=2 S_{\text {planar }} / W$, from which $S_{\text {planar }}=W / 2 \times \tau_{\text {eff. }}$ The surface recombination velocity of each textured surface $S_{\text {textured }}$ for one-sided textured wafers can then calculated as $S_{\text {textured }}=W / \tau_{\text {eff }}-S_{\text {planar. }}$. Results of calculations of $S_{\text {textured }}$ are presented in the bottom panel of Figure 4. The calculated average $S_{\text {textured }}$ for $t_{\mathrm{RIE}}$ of 1.5, 2 and $3 \mathrm{~min}$ is below $10 \mathrm{~cm} \mathrm{~s}^{-1}\left(6.9,8.7\right.$ and $9.7 \mathrm{~cm} \mathrm{~s}^{-1}$ respectively). For comparison, $S_{\text {planar }}$ is $6.8 \mathrm{~cm} \mathrm{~s}^{-1}$ for the nontextured wafer. $S_{\text {textured }}$ increases for longer $t_{\mathrm{RIE}}$, however not dramatically. Texturing Si with CCP instead results in a $5 \mathrm{x}$ increase of $S_{\text {textured }}$ to $49.4 \mathrm{~cm} \mathrm{~s}^{-1}$. Extracting $S_{\text {textured }}$ from the stabilized lifetime data results in values close to $S_{\text {planar }}\left(10.6 \mathrm{~cm} \mathrm{~s}^{-1}\right)$ only for $t_{\mathrm{RIE}}$ of 1.5 and 2 $\min \left(12.9 \mathrm{~cm} \mathrm{~s}^{-1}\right.$ and $13.6 \mathrm{~cm} \mathrm{~s}^{-1}$, respectively). We note that texturing with ICP for 3 min or

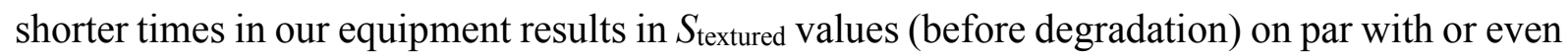
better than the state-of-the-art for p-type $\mathrm{CZ}\left(11 \mathrm{~cm} \mathrm{~s}^{-1}\right.$ in the review by Otto et al. ${ }^{[3]}, 20 \mathrm{~cm} \mathrm{~s}^{-1}$ in the record $\mathrm{b}$-Si cells by Savin et al. ${ }^{[27]}$ and $10 \mathrm{~cm} \mathrm{~s}^{-1}$ reported by Allen et al. $\left.{ }^{[36]}\right)$. This indicates potential for further efficiency improvements of $b$-Si solar cells made by RIE texturing, if CCP is omitted from the texturing process. For instance, given $S_{\text {planar }}=6.7 \mathrm{~cm} \mathrm{~s}^{-1}$ and $S_{\text {textured }}=8.7$ $\mathrm{cm} \mathrm{s}^{-1}$, the implied open circuit voltage $i V_{\mathrm{oc}}$ of a cell with thickness of $180 \mu \mathrm{m}$ would be 757 $\mathrm{mV}$ (see calculation in the Supporting Information). Even including losses due to e.g. metallization, this would enable substantial advancements in state-of-the-art of solar cells with b-Si texturing.

\section{Conclusions}

We have developed a recipe to texture Si surfaces using non-cryogenic reactive ion etch with a plasma sustained exclusively by inductively coupled power. We achieved a target reflectance of $3 \%$ or lower in the wavelength range 300-1000 $\mathrm{nm}$ after just 2 min of etch time. Measurements of effective minority carrier lifetime of wafers coated by $\mathrm{Al}_{2} \mathrm{O}_{3}$ deposited by 
atomic layer deposition showed values in excess of $3 \mathrm{~ms}$ for etching time equal to or shorter than 3 min on p-type $\mathrm{CZ}$ wafers. The passivation offered by $\mathrm{Al}_{2} \mathrm{O}_{3}$ degraded by approximately $50 \%$ before stabilizing after around $200 \mathrm{~h}$, however it could be recovered by simple annealing at $150{ }^{\circ} \mathrm{C}$ in ambient atmosphere on a hotplate and degradation could be avoided on nontextured wafers employing a $\mathrm{SiN}_{\mathrm{x}}: \mathrm{H}$ capping layer. We calculated values of surface recombination velocity of textured surfaces as low as $6.9 \mathrm{~cm} \mathrm{~s}^{-1}$ before degradation, which is better than state-of-the-art for p-type CZ Si textured by reactive ion etch. Fabrication of solar cells with several architectures sharing the front surface texturing developed here is under progress and will be the subject of a future report.

\section{Experimental Section}

\subsection{Fabrication}

All wafers were $150 \mathrm{~mm}$ diameter, $500 \mu \mathrm{m}$ thick CZ p-type Si (100). Wafers were textured on one side using an ICP RIE tool (MP0637) from SPTS using the following parameters: process temperature of $0{ }^{\circ} \mathrm{C}, \mathrm{SF}_{6}$ and $\mathrm{O}_{2}$ plasma with flow ratio of $\mathrm{SF}_{6}: \mathrm{O}_{2} \sim 1: 1$, total pressure of 24 mTorr. For each wafer the plasma was sustained using either an ICP of $1500 \mathrm{~W}$, or a CCP of $100 \mathrm{~W}$. The process time $t_{\mathrm{RIE}}$ was varied between 1.5 and $20 \mathrm{~min}$. All wafers (including nontextured wafers for reference purposes) were cleaned using a standard cleaning (SC) procedure ( $\mathrm{SC} 1: 10$ min in a $\mathrm{NH}_{4} \mathrm{OH}: \mathrm{H}_{2} \mathrm{O}_{2}: \mathrm{H}_{2} \mathrm{O}=1: 1: 5$ solution at $70{ }^{\circ} \mathrm{C}$; $\mathrm{SC} 2: 10$ min in a $\mathrm{HCl}: \mathrm{H}_{2} \mathrm{O}_{2}: \mathrm{H}_{2} \mathrm{O}$ $=1: 1: 5$ solution at $70{ }^{\circ} \mathrm{C}$ ). The $\mathrm{SiO}_{2}$ layer grown during $\mathrm{SC} 1$ was removed by a $30 \mathrm{~s}$ dip in diluted $\mathrm{HF}(5 \%)$ at room temperature. The $\mathrm{SiO}_{2}$ layer grown during $\mathrm{SC} 2$ was not removed. Surfaces were passivated by $\mathrm{Al}_{2} \mathrm{O}_{3}$ using 380 cycles of thermal atomic layer deposition (ALD) at $200{ }^{\circ} \mathrm{C}$ using a R200 tool (Picosun). Trimethylalane (TMA) and water were used as precursors for $\mathrm{Al}$ and $\mathrm{O}$, respectively. In order to activate the passivation, wafers were annealed in a Tempress furnace at $400{ }^{\circ} \mathrm{C}$ for $10 \mathrm{~min}$ in a $\mathrm{N}_{2}$ atmosphere. Capping layers of $75 \mathrm{~nm} \mathrm{SiN} \mathrm{x}: \mathrm{H}$ were deposited by plasma enhanced chemical vapor deposition at $300{ }^{\circ} \mathrm{C}$ in a Multiplex PECVD system (SPTS).

\subsection{Characterization}

The total (diffuse + specular) optical reflectance $R$ was measured using a QEXL system (PV measurements) equipped with an integrating sphere. The optical transmittance $T$ was measured using a UV spectrophotometer (UV-2600, Shimadzu Co.). Scanning electron microscopy (SEM) images were acquired using a Supra 40VP microscope (Carl Zeiss) at an acceleration 
voltage of $5 \mathrm{kV}$. Effective minority carrier lifetime $\tau_{\text {eff }}$ was measured with a MDPmap tool (Freiberg Instruments). Lifetime values were extracted at an injection level of $10^{15} \mathrm{~cm}^{-3}$ and averaged over a $100 \mathrm{~mm}$ diameter area in the center of each $150 \mathrm{~mm}$ wafer, due to known edge effects of the passivation process.

\section{Author Information}

Corresponding Authors: benian@,nanotech.dtu.dk. Tel: +45 45258167

\section{Notes}

The authors declare no competing financial interest.

\section{Acknowledgements}

This project is supported by funding from EUDP (project number 64016-0030). B.I. thanks Io Mizushima at IPU for help with the optical transmittance measurements.

\section{References}

[1] H. Jansen, M. De Boer, R. Legtenberg, M. Elwenspoek, J. Micromechanics Microengineering 1995, 5, 115.

[2] X. Liu, P. R. Coxon, M. Peters, B. Hoex, J. M. Cole, D. J. Fray, Energy Environ. Sci. 2014, 7, 3223 .

[3] M. Otto, M. Algasinger, H. Branz, B. Gesemann, T. Gimpel, K. Füchsel, T. Käsebier, S. Kontermann, S. Koynov, X. Li, V. Naumann, J. Oh, A. N. Sprafke, J. Ziegler, M. Zilk, R. B. Wehrspohn, Adv. Opt. Mater. 2015, 3, 147.

[4] H. Huang, J. Lv, Y. Bao, R. Xuan, S. Sun, S. Sneck, Sol. Energy Mater. Sol. Cells 2017, 161, 14 .

[5] M. Broas, H. Jiang, A. Graff, T. Sajavaara, V. Vuorinen, M. Paulasto-kröckel, Appl. Phys. Lett. 2017, 141606.

[6] S. Miyajima, J. Irikawa, A. Yamada, M. Konagai, 2010.

[7] B. Iandolo, M. Plakhotnyuk, M. Gaudig, R. S. Davidsen, D. Lausch, O. Hansen, Proc. 33rd Eur. Photovolt. Sol. Energy Conf. Exhib. 2017, 841.

[8] A. K. Katiyar, S. Mukherjee, M. Zeeshan, S. K. Ray, A. K. Raychaudhuri, ACS Appl. Mater. Interfaces 2015, 7, 23445.

[9] C. Cho, D. Kong, J. H. Oh, B. Kim, B. Lee, J. Lee, Phys. Status Solidi Appl. Mater. Sci. 2014, 211, 1844.

[10] T. Rahman, R. S. Bonilla, A. Nawabjan, P. R. Wilshaw, S. A. Boden, Sol. Energy 
Mater. Sol. Cells 2017, 160, 444.

[11] T. Rahman, S. A. Boden, IEEE J. Photovoltaics 2017, 7, 1556.

[12] P. Repo, J. Benick, V. Vähänissi, J. Schön, G. Von Gastrow, B. Steinhauser, M. C. Schubert, M. Hermle, H. Savin, Energy Procedia 2013, 38, 866.

[13] W. C. Wang, C. W. Lin, H. J. Chen, C. W. Chang, J. J. Huang, M. J. Yang, B. Tjahjono, J. J. Huang, W. C. Hsu, M. J. Chen, ACS Appl. Mater. Interfaces 2013, 5, 9752.

[14] J. M. Shim, H. W. Lee, K. Y. Cho, J. K. Seo, J. S. Kim, E. J. Lee, J. Y. Choi, D. J. Oh, J. E. Shin, J. S. Kim, J. H. Kong, S. H. Lee, H. S. Lee, Int. J. Photoenergy 2012, 2012.

[15] Y. Liu, T. Lai, H. Li, Y. Wang, Z. Mei, H. Liang, Z. Li, F. Zhang, W. Wang, A. Y. Kuznetsov, X. Du, Small 2012, 8, 1392.

[16] B. Iandolo, I. Mizushima, R. S. Davidsen, P. T. Tang, O. Hansen, Jpn. J. Appl. Phys. 2018, 57,1 .

[17] T. Pasanen, V. Vähänissi, N. Theut, H. Savin, Energy Procedia 2017, 124, 307.

[18] M. Otto, M. Kroll, T. Käsebier, R. Salzer, A. Tünnermann, R. B. Wehrspohn, Appl. Phys. Lett. 2012, 100, 1.

[19] B. Kafle, J. Seiffe, M. Hofmann, L. Clochard, E. Duffy, J. Rentsch, Phys. Status Solidi Appl. Mater. Sci. 2015, 212, 307.

[20] B. Kafle, T. Freund, A. Mannan, L. Clochard, E. Duffy, S. Werner, P. Saint-Cast, M. Hofmann, J. Rentsch, R. Preu, Energy Procedia 2016, 92, 359.

[21] B. Kafle, A. I. Ridoy, P. Saint-Cast, L. Clochard, E. Duffy, K. Duncker, K. Petter, M. Hofmann, J. Rentsch, AIP Conf. Proc. 2018, 1999.

[22] V. Pontevedra, A. Kumar, S. N. Melkote, Procedia Manuf. 2018, 21, 549.

[23] M. Steglich, T. Käsebier, M. Zilk, T. Pertsch, E. Kley, M. Zilk, T. Pertsch, J. Appl. Phys. 2017, 173503.

[24] D. A. Saab, P. Basset, M. J. Pierotti, M. L. Trawick, D. E. Angelescu, Appl. Phys. Lett. 2014, $265502,1$.

[25] R. S. Davidsen, H. Li, A. To, X. Wang, A. Han, J. An, J. Colwell, C. Chan, A. Wenham, M. S. Schmidt, A. Boisen, O. Hansen, S. Wenham, A. Barnett, Sol. Energy Mater. Sol. Cells 2016, 144, 740.

[26] J. Oh, H. C. Yuan, H. M. Branz, Nat. Nanotechnol. 2012, 7, 743.

[27] H. Savin, P. Repo, G. Von Gastrow, P. Ortega, E. Calle, M. Garín, R. Alcubilla, Nat. Nanotechnol. 2015, 10, 624.

[28] J. Benick, A. Richter, R. Müller, H. Hauser, F. Feldmann, P. Krenckel, S. Riepe, F. 
Schindler, M. C. Schubert, M. Hermle, A. W. Bett, S. W. Glunz, IEEE J. Photovoltaics 2017, 7, 1171.

[29] M. M. Plakhotnyuk, M. Gaudig, R. S. Davidsen, J. M. Lindhard, J. Hirsch, D. Lausch, M. S. Schmidt, E. Stamate, O. Hansen, J. Appl. Phys. 2017, 122.

[30] M. Gaudig, J. Hirsch, T. Schneider, A. N. Sprafke, J. Ziegler, N. Bernhard, R. B. Wehrspohn, J. Vac. Sci. Technol. A Vacuum, Surfaces, Film. 2015, 33, $05 \mathrm{E} 132$.

[31] J. Hirsch, M. Gaudig, N. Bernhard, D. Lausch, Appl. Surf. Sci. 2016, 374, 252.

[32] E. Yablonovitch, J. Opt. Soc. Am. 1982, 72, 899.

[33] J. Penaud, A. Rothschild, P. Jaffrennou, R. Naber, M. Ngamo, B. Lombardet, In 2011 37th IEEE Photovoltaic Specialists Conference; IEEE, 2011; pp. 001498-001503.

[34] D. Sperber, A. Herguth, G. Hahn, Energy Procedia 2016, 92, 211.

[35] T. Niewelt, W. Kwapil, M. Selinger, A. Richter, M. C. Schubert, IEEE J. Photovoltaics 2017, 7, 1197.

[36] T. Allen, J. Bullock, A. Cuevas, S. Baker-Finch, F. Karouta, 2014 IEEE 40th Photovolt. Spec. Conf. PVSC 2014 2014, 562. 